Article

\title{
Preparation of Soluble POSS-Linking Polyamide and Its Application in Antifogging Films
}

\author{
Tomoya Kozuma, Aki Mihata and Yoshiro Kaneko * \\ Graduate School of Science and Engineering, Kagoshima University, Kagoshima 890-0065, Japan; \\ k6225066@kadai.jp (T.K.); mihata@eng.kagoshima-u.ac.jp (A.M.) \\ * Correspondence: ykaneko@eng.kagoshima-u.ac.jp; Tel.: +81-99-285-7794
}

check for updates

Citation: Kozuma, T.; Mihata, A.; Kaneko, Y. Preparation of Soluble POSS-Linking Polyamide and Its Application in Antifogging Films. Materials 2021, 14, 3178. https:// doi.org/10.3390/ma14123178

Academic Editors: Beata Dudziec and Krzysztof Matyjaszewski

Received: 19 May 2021

Accepted: 7 June 2021

Published: 9 June 2021

Publisher's Note: MDPI stays neutral with regard to jurisdictional claims in published maps and institutional affiliations.

Copyright: (c) 2021 by the authors. Licensee MDPI, Basel, Switzerland. This article is an open access article distributed under the terms and conditions of the Creative Commons Attribution (CC BY) license (https:// creativecommons.org/licenses/by/ $4.0 /)$.
Abstract: In this study, we prepared a polyhedral oligomeric silsesquioxane (POSS)-linking polyamide (POSS polyamide) by a polycondensation of ammonium-functionalized POSS (POSS-A) and carboxylfunctionalized POSS (POSS-C) in dehydrated dimethyl sulfoxide (DMSO) using 1-(3-dimethylaminopropyl)-3-ethylcarbodiimide hydrochloride (EDC) and $\mathrm{N}$-hydroxysuccinimide (NHS) as condensing agents. The obtained POSS polyamide was soluble in various highly polar solvents, and it could form a self-standing film. FT-IR, ${ }^{1} \mathrm{H}$ NMR, and ${ }^{29} \mathrm{Si}$ NMR analyses showed that POSS polyamide is a polymer in which POSS-A and POSS-C are linked almost linearly by amide bonds. Furthermore, the cast film obtained by heat-treating the polymer at $150{ }^{\circ} \mathrm{C}$ for $30 \mathrm{~min}$ exhibited excellent transparency and hard-coating (pencil scratch test: $5 \mathrm{H}$ ) and antifogging properties (evaluation by water vapor exposure).

Keywords: antifogging; hard-coating; silsesquioxane; POSS; polyamide

\section{Introduction}

Fogging occurs when water vapor condenses on a cold surface to form droplets large enough to scatter light. Fogging on transparent surfaces causes inconvenience in not only daily life, such as automobile windshields, eyeglasses/goggles, and bathroom mirrors but also advanced technology, such as solar cells and analytical/medical equipment. Therefore, there is a need for techniques to suppress fogging. Thus far, various antifogging materials have been developed [1,2]. Two strategies are widely employed to develop antifogging materials. First, making super-water-repellent (superhydrophobic) surfaces on which water droplets cannot adhere. Second, forming superhydrophilic surfaces on which a uniform water film that does not scatter light can be formed.

In the first method, excellent water-repellent materials derived from the combination of nanoscale surface roughness and low surface free energy have been considered candidates for antifogging films [3-5]. However, it is still technically very difficult to produce the complex morphology of these surfaces on large areas. In addition, super-water-repellent coatings having a concavo-convex structure on the surface are generally opaque, which further limits their applications as an antifogging film.

On the other hand, in the second method, superhydrophilic materials have been developed to produce antifogging surfaces. Forming a thin water layer on a surface can significantly reduce light scattering caused by water droplets. Titanium oxide $\left(\mathrm{TiO}_{2}\right)$, which exhibits a transition to superhydrophilicity after ultraviolet (UV) irradiation, is used as an antifogging film [6-8]. The water contact angle on the $\mathrm{TiO}_{2}$ surface becomes less than $5^{\circ}$ after UV irradiation. However, without UV irradiation, $\mathrm{TiO}_{2}$ is not superhydrophilic, thus not suitable for such applications at night. Therefore, combining with silica $\left(\mathrm{SiO}_{2}\right)$ was reported as a success for hydrophilic $\mathrm{TiO}_{2}$-based materials [9-12]. Furthermore, transparent and mechanically robust superhydrophilic silica coatings prepared by the sol-gel method followed by calcination have been reported [13]. However, since treatment at a considerably 
high temperature $\left(400^{\circ} \mathrm{C}\right)$ is necessary for preparing the film, antifogging films based on these inorganic compounds are effective only on inorganic substrates.

Many hydrophilic organic polymer coatings have been reported [14-19]. Such surfaces primarily have several strong hydrophilic groups, such as hydroxy, carboxyl, ammonium, and sulfo groups. In addition, coatings that skillfully combine hydrophilic poly(ethylene glycol) (PEG) segments and hydrophobic perfluoroalkyl group segments exhibit antifogging properties [20]. However, the hardness of organic polymers is generally lower than that of inorganic materials, although acrylate-based hard-coating has been achieved by hybridizing with silica [21]. The low surface hardness makes it difficult to use organic materials in optical applications as the surface is easily scratched by rubbing and scuffing, and the scratches cause light-scattering.

Based on this research, we focused on polyhedral oligomeric silsesquioxane (POSS)linking polymers, which combine high hardness, such as inorganic materials, and ease of handling, such as organic polymers. The purpose of this study is to develop cast films that exhibit both hard-coating and antifogging properties by using such POSS-linking polymers.

POSS has a well-defined cage or dice structure. It has attracted a lot of attention in academic and industrial research as an inorganic framework compound [22-31]. In particular, POSS has been extensively used as inorganic fillers in polymer matrices [32]. This is because it significantly improves the thermal and mechanical properties of the original polymers when appropriate groups compatible with the polymer matrices are presented in side chains of POSS.

Meanwhile, since POSS is an oligomer, it is difficult to apply it alone as films and bulk materials. Thus, recently, POSS-linking polymers have been prepared. However, because POSS generally has multiple functional groups, a polymer resulting from its polymerization usually forms a network structure and becomes insoluble. To prepare soluble POSS-linking polymers, it is necessary to prepare POSSs in which the number and arrangement of different substituents are controlled [33-39]. However, complex reactions and purification processes are required to prepare such POSSs. Meanwhile, in our previous study, we found that a POSS-linking polymer could be easily prepared by the hydrolytic condensation of a mixture of 3-(2-aminoethylamino)propyltrimethoxysilane and bis [3-(trimethoxysilyl)propyl]amine in a superacid trifluoromethanesulfonic acid (HOTf) aqueous solution [40]. The problem with this polymer is that it cannot form a self-standing film, probably because the alkylammonium group linking POSSs has a flexible structure.

Before the above-cited study, we reported that ammonium-functionalized POSS (POSS-A) could be easily prepared by the hydrolytic condensation of 3-aminopropyltrimethoxysilane (APTMS) in aqueous HOTf [41-46]. In this method, because the reaction solution is concentrated and the solvent is finally completely evaporated, POSS can be prepared in higher yields and shorter times. Even in such a concentration method, gelation or polymerization does not occur when superacid is used. Furthermore, we prepared carboxylfunctionalized POSS (POSS-C) [47] by the heat treatment of carboxyl-functionalized rodlike polysilsesquioxane [48] in aqueous HOTf.

Here, when POSS-A and POSS-C were polycondensed using 1-(3-dimethylaminopropyl)-3-ethylcarbodiimide hydrochloride (EDC) and N-hydroxysuccinimide (NHS) as condensing agents, a soluble POSS-linking polymer (POSS polyamide), which can form a self-standing film, was obtained. Furthermore, the cast film obtained from POSS polyamide exhibited both hard-coating and antifogging properties.

\section{Materials and Methods}

\subsection{Materials}

APTMS (purity: 96\%), 2-cyanoethyltriethoxysilane (CETES) (purity: 97\%), EDC (purity: 98\%), tetramethylsilane (TMS) (purity: 99\%), and tris(2,4-pentanedionato)chromium(III) [Cr(acac) $)_{3}$ (purity: 98\%) were purchased from Tokyo Chemical Industry Co., Ltd. (Tokyo, Japan). HOTf (purity: 99\%) was obtained from Kanto Chemical Co., Inc. (Tokyo, Japan). Sodium hydroxide $(\mathrm{NaOH})$ (purity: $97 \%$ ), NHS (purity: $95 \%$ ), and potassium bromide 
(KBr) (purity: 99\%) were purchased from Nacalai Tesque Inc. (Kyoto, Japan). Dimethyl sulfoxide (DMSO) (purity: 99\%) and other solvents were obtained from FUJIFILM Wako Pure Chemical Co., Ltd. (Osaka, Japan). The DMSO used in the preparation of POSS polyamide was simply dehydrated by adding molecular sieves $3 \mathrm{~A}$, which had been dried in an oven at $100{ }^{\circ} \mathrm{C}$ for over 1 day. Other reagents and solvents were used without further purification.

\subsection{Preparation of POSS- $A$}

POSS-A was prepared with minor modifications to the procedures reported in the literature [41,43]. A $0.5 \mathrm{~mol} \mathrm{~L}^{-1}$ HOTf aqueous solution $(99 \mathrm{~mL}, 49.5 \mathrm{mmol})$ was added to APTMS (5.681 g, $30.42 \mathrm{mmol}$ ) with stirring at room temperature. The resulting solution was further stirred at room temperature for $30 \mathrm{~min}$ and then heated at ca. $50{ }^{\circ} \mathrm{C}$ in an open system until the solvent completely evaporated (ca. $4 \mathrm{~h}$ ). After the crude product was maintained at $100{ }^{\circ} \mathrm{C}$ for $2 \mathrm{~h}$, an acetone-chloroform mixed solvent $(1: 1 v / v$, ca. $200 \mathrm{~mL})$ was added at room temperature. The insoluble product was isolated by filtration, washed with this mixed solvent (ca. $50 \mathrm{~mL}$, three times), and then dried under reduced pressure at room temperature to yield a white powdered product ( $8.260 \mathrm{~g}$, quantitative yield).

\subsection{Preparation of Carboxyl-Functionalized Rod-Like Polysilsesquioxane as a Precursor of POSS-C}

Carboxyl-functionalized rod-like polysilsesquioxane was prepared with minor modifications to the procedures reported in the literature [48]. After a $2.0 \mathrm{~mol}, \mathrm{~L}^{-1} \mathrm{NaOH}$ aqueous solution $(60 \mathrm{~mL}, 120 \mathrm{mmol})$ was added to CETES $(8.962 \mathrm{~g}, 40 \mathrm{mmol})$ with stirring at room temperature, the resulting solution was further stirred for $15 \mathrm{~h}$, followed by heating at ca. $50{ }^{\circ} \mathrm{C}$ in an open system until the solvent completely evaporated. After the crude product was maintained at $100{ }^{\circ} \mathrm{C}$ for $2 \mathrm{~h}$, a $1.0 \mathrm{~mol} \mathrm{~L}^{-1}$ hydrochloric acid $(\mathrm{HCl})$ aqueous solution $(120 \mathrm{~mL}, 120 \mathrm{mmol})$ was added at room temperature. The resulting suspension was stirred at room temperature for $1.5 \mathrm{~h}$ and then at $50{ }^{\circ} \mathrm{C}$ for $30 \mathrm{~min}$ until a clear and colorless solution was obtained. Then, this solution was heated at ca. $50{ }^{\circ} \mathrm{C}$ in an open system until the solvent completely evaporated (ca. $6 \mathrm{~h}$ ). Water $(25 \mathrm{~mL})$ was added to the obtained solid product, and the mixture was quickly stirred with a spatula for $1 \mathrm{~min}$, and suction filtration was performed immediately to remove sodium chloride produced by the reaction of $\mathrm{NaOH}$ and $\mathrm{HCl}$ aqueous solutions. The product was also dissolved in water by stirring for a long time, and so it is important to stir quickly and filter immediately. This operation was performed a total of 3 times. The resulting solid was dried under reduced pressure at room temperature to yield a white powdered product (5.239 g, quantitative yield).

\subsection{Preparation of POSS-C}

POSS-C was prepared with minor modifications to the procedures reported in the literature [47]. First, a $0.50 \mathrm{~mol} \mathrm{~L}^{-1}$ HOTf aqueous solution $(100 \mathrm{~mL}, 50 \mathrm{mmol})$ was added to carboxyl-functionalized rod-like polysilsesquioxane $(4.171 \mathrm{~g}, 33.33 \mathrm{mmol}$ unit). Then, the system was heated at ca. $60^{\circ} \mathrm{C}$ for $10 \mathrm{~min}$, and the resulting solution was stirred at room temperature for $2 \mathrm{~h}$. Thereafter, the solution was heated at ca. $50{ }^{\circ} \mathrm{C}$ in an open system until the solvent completely evaporated (ca. $5.5 \mathrm{~h}$ ). At this stage, the solution was in a liquid state because HOTf remained. The resulting liquid was maintained in an oven at $100{ }^{\circ} \mathrm{C}$ for $2 \mathrm{~h}$. The product was cooled to room temperature, and then acetone $(8.4 \mathrm{~mL})$ was added. The resulting solution was poured into an acetone-chloroform mixed solvent $(1: 9 \mathrm{v} / \mathrm{v}, 416 \mathrm{~mL})$ and stirred $(650 \mathrm{rpm})$ at room temperature for $15 \mathrm{~h}$. Subsequently, the insoluble part was isolated by filtration and washed with acetonitrile (ca. $25 \mathrm{~mL}$, five times). Finally, it was dried under reduced pressure to yield a white powdered product (1.302 g, yield $31 \%$ ).

\subsection{Preparation of POSS Polyamide}

To a solution of POSS-C (1.252 g, $10 \mathrm{mmol}$ unit) in dehydrated DMSO (50 mL), a solution of POSS-A (2.603 g, $10 \mathrm{mmol}$ unit), EDC (2.934 g, $15 \mathrm{mmol})$, and NHS (1.817 g, 
$15 \mathrm{mmol})$ in dehydrated DMSO $(150 \mathrm{~mL})$ was added, and the resulting solution was stirred at ca. $80^{\circ} \mathrm{C}$ for $12 \mathrm{~h}$. The resulting solution was poured into acetone (ca. $2000 \mathrm{~mL}$ ) and stirred at room temperature for $2 \mathrm{~h}$. Subsequently, the insoluble part was isolated by decantation, and methanol $(30 \mathrm{~mL})$ was added. The resulting solution was poured into acetone (ca. $1000 \mathrm{~mL}$ ), and the insoluble part was isolated by filtration and washed with acetone (ca. $25 \mathrm{~mL}$, five times). Then, $N, N$-dimethylformamide (DMF) $(40 \mathrm{~mL}$ ) at ca. $80^{\circ} \mathrm{C}$ was added. The resulting suspension was stirred at ca. $80^{\circ} \mathrm{C}$ for $15 \mathrm{~min}$, and the soluble part was isolated by filtration and concentrated to ca. $2 \mathrm{~mL}$ using a rotary evaporator. The concentrated solution was added to acetone (ca. $60 \mathrm{~mL})$, and the insoluble part was isolated by filtration and washed with acetone (ca. $25 \mathrm{~mL}$, five times). Finally, the product was dried under reduced pressure to yield a white powdered POSS polyamide $(0.531 \mathrm{~g}$, yield $18 \%)$. The ideal chemical formulas of the repeating units of the ammonium component $\left[\mathrm{SiO}_{1.5}\left(\mathrm{CH}_{2}\right)_{3} \mathrm{NH}_{3} \mathrm{Cl}, \mathrm{FW}=146.7\right]$, carboxyl component $\left[\mathrm{SiO}_{1.5}\left(\mathrm{CH}_{2}\right)_{2} \mathrm{COOH}\right.$, $\mathrm{FW}=125.2]$, and amide component $\left[\mathrm{SiO}_{1.5}\left(\mathrm{CH}_{2}\right)_{3} \mathrm{NHCO}\left(\mathrm{CH}_{2}\right)_{2} \mathrm{SiO}_{1.5}, \mathrm{FW}=217.3\right]$ (compositional ratio of ammonium:carboxyl:amide components $=40: 45: 15)$ of this product was used for the determination. ${ }^{1} \mathrm{H}$ NMR $\left(400 \mathrm{MHz}, \mathrm{DMSO}-d_{6}\right)$ : $\delta$ 12.26-11.93 (br, $-\mathrm{C}(=\mathrm{O}) \mathrm{OH}), \delta 8.32-8.10\left(\mathrm{br},-\mathrm{SiCH}_{2} \mathrm{CH}_{2} \mathrm{CH}_{2} \mathrm{NH}_{3}\right), \delta 8.10-7.86(\mathrm{br},-\mathrm{C}(=\mathrm{O}) \mathrm{NH}-), \delta 3.06-2.92$ (br, $-\mathrm{SiCH}_{2} \mathrm{CH}_{2} \mathrm{CH}_{2} \mathrm{NHC}(=\mathrm{O})-$ ), $\delta$ 2.90-2.69 (br, $-\mathrm{SiCH}_{2} \mathrm{CH}_{2} \mathrm{CH}_{2} \mathrm{NH}_{3}$ ), $\delta$ 2.44-2.35 (br, $\left.-\mathrm{SiCH}_{2} \mathrm{CH}_{2} \mathrm{C}(=\mathrm{O}) \mathrm{NH}-\right), \delta 2.32-2.13\left(\mathrm{br},-\mathrm{SiCH}_{2} \mathrm{CH}_{2} \mathrm{C}(=\mathrm{O}) \mathrm{OH}\right), \delta 1.82-1.56\left(\mathrm{br},-\mathrm{SiCH}_{2} \mathrm{CH}_{2}\right.$ $\left.\mathrm{CH}_{2} \mathrm{NH}_{3}\right), \delta 1.56-1.32\left(\mathrm{br},-\mathrm{SiCH}_{2} \mathrm{CH}_{2} \mathrm{CH}_{2} \mathrm{NHC}(=\mathrm{O})-\right), \delta 0.94-0.76\left(\mathrm{br},-\mathrm{SiCH}_{2} \mathrm{CH}_{2} \mathrm{C}(=\mathrm{O}) \mathrm{OH}\right.$, $\left.-\mathrm{SiCH}_{2} \mathrm{CH}_{2} \mathrm{C}(=\mathrm{O}) \mathrm{NH}-\right)$, $\delta 0.76-0.66\left(\mathrm{br},-\mathrm{SiCH}_{2} \mathrm{CH}_{2} \mathrm{CH}_{2} \mathrm{NH}_{3}\right), \delta 0.66-0.44\left(\mathrm{br},-\mathrm{SiCH}_{2} \mathrm{CH}_{2}\right.$ $\left.\mathrm{CH}_{2} \mathrm{NHC}(=\mathrm{O})-\right) .{ }^{29} \mathrm{Si} \mathrm{NMR}\left(79.4 \mathrm{MHz}, \mathrm{DMSO}-d_{6}\right): \delta-65.27--66.87\left(\mathrm{~T}^{3}, \mathrm{~T}_{8}\right.$-POSS $), \delta$ $-66.87--69.50\left(\mathrm{~T}^{3}, \mathrm{~T}_{10}\right.$-POSS), $\delta-69.50--71.37\left(\mathrm{~T}^{3}, \mathrm{~T}_{12}\right.$-POSS). FT-IR (KBr): $1724 \mathrm{~cm}^{-1}$ $(-\mathrm{C}(=\mathrm{O}) \mathrm{OH}), 1631 \mathrm{~cm}^{-1}(-\mathrm{C}(=\mathrm{O}) \mathrm{NH}-), 1115 \mathrm{~cm}^{-1}$ ( $\left.\mathrm{Si}-\mathrm{O}-\mathrm{Si}\right)$.

\subsection{Preparation of the Cast Film of POSS Polyamide}

An aqueous solution prepared by dissolving POSS polyamide $(0.025 \mathrm{~g})$ in water $(0.10 \mathrm{~mL})$ was applied to a glass plate whose surface was polished using a cerium oxide powder. Then, the glass plate was heated on a hot plate (setting temperature: $80^{\circ} \mathrm{C}$ ) for $30 \mathrm{~min}$ to evaporate water, and then maintained in an oven at $150^{\circ} \mathrm{C}$ for $30 \mathrm{~min}$.

\subsection{Measurements}

The FT-IR spectra were recorded using an FT/IR-4200 spectrometer (JASCO Corporation, Tokyo, Japan). The ${ }^{1} \mathrm{H}$ and ${ }^{29} \mathrm{Si}$ NMR spectra were recorded using an ECX-400 spectrometer (JEOL RESONANCE Inc., Tokyo, Japan). Thermogravimetric analyses (TGA) were performed using TGA-50 (SHIMADZU Co., Kyoto, Japan). To remove a small amount of solvent in the samples, they were first kept at $120{ }^{\circ} \mathrm{C}$ for 30 min under nitrogen flow $\left(100 \mathrm{~mL} \mathrm{~min}^{-1}\right)$. Then, after cooling to room temperature, they were heated to $1000{ }^{\circ} \mathrm{C}$ at a heating rate of $10^{\circ} \mathrm{C} \mathrm{min}^{-1}$ under nitrogen flow $\left(100 \mathrm{~mL} \mathrm{~min}^{-1}\right)$. The pencil hardness was measured using a pencil scratch tester (TP GIKEN Co., Osaka, Japan) with the pencil at an angle of $45^{\circ}$ under a $750 \mathrm{~g}$ loading. The pencil used was made by Mitsubishi Pencil Co., Ltd. (Tokyo, Japan). The lead of the pencils was ground perpendicularly to make an angle of $90^{\circ}$ before measuring the pencil hardness each time. The water repellence of the cast films was evaluated using a water-drop contact-angle meter (SImage Entry 6, Excimer, Inc., Kanagawa, Japan). The amount of water was $2.6 \mu \mathrm{L}$, and the water-drop contact angle taken with a CCD camera was measured using the half-angle method.

\section{Results and Discussion}

\subsection{Preparation and Characterizations of POSS Polyamide}

POSS polyamide was prepared by the polycondensation of POSS-A and POSS-C in the presence of EDC and NHS. A solution of POSS-A, POSS-C, EDC, and NHS in dehydrated DMSO was heated at ca. $80{ }^{\circ} \mathrm{C}$ for $12 \mathrm{~h}$ (Scheme 1). After cooling to room temperature, the solution was reprecipitated from acetone and stirred for $2 \mathrm{~h}$. After filtration, the residue was washed with acetone and added DMF. This suspension was 
stirred at ca. $80{ }^{\circ} \mathrm{C}$ for $15 \mathrm{~min}$. Then the soluble part was isolated by filtration and reprecipitated from acetone. After filtration, the residue was washed with acetone and dried under reduced pressure to obtain POSS polyamide. The precipitation was repeated, as described above, to remove POSS-C as an acetone-soluble part and POSS-A as a DMFinsoluble part. The counterion of an unreacted POSS-A was converted to a chloride ion derived from EDC. POSS-A, whose counterion is a chloride ion, was insoluble in DMF. The solubility of POSS polyamide and the starting materials is shown in Table 1.
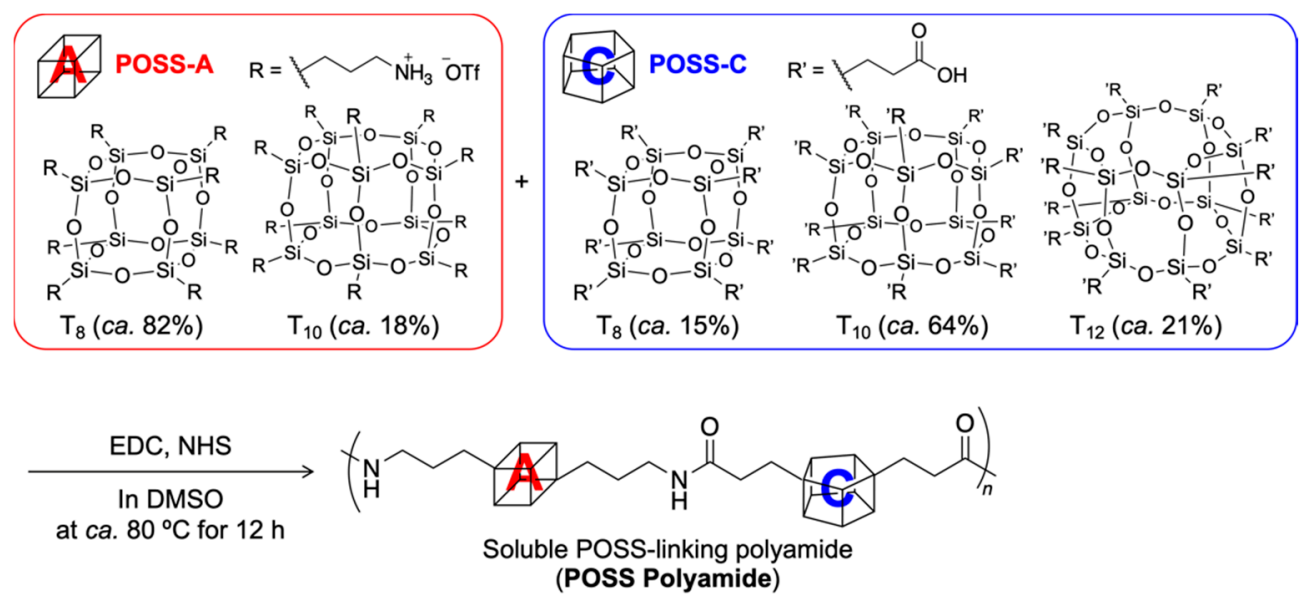

Scheme 1. Preparation of POSS polyamide.

Table 1. Solubility of POSS-A, POSS-C, and POSS polyamide.

\begin{tabular}{|c|c|c|c|c|c|c|c|c|c|}
\hline \multirow{2}{*}{ Compound } & \multicolumn{9}{|c|}{ Solubility ${ }^{1}$} \\
\hline & Water & DMSO $^{2}$ & $\mathrm{DMF}^{2}$ & $\mathrm{MeOH}^{2}$ & $\mathrm{Me}_{2} \mathrm{CO}^{2}$ & $\mathrm{AcOEt}^{2}$ & $\mathrm{CHCl}_{3}{ }^{2}$ & Toluene & Hexane \\
\hline POSS-A & + & + & + & + & - & - & - & - & - \\
\hline $\begin{array}{c}\text { POSS-A } \\
\left(\text { Counterion: } \mathrm{Cl}^{-}\right)\end{array}$ & + & + & - & + & - & - & - & - & - \\
\hline POSS-C & + & + & + & + & + & - & - & - & - \\
\hline $\begin{array}{c}\text { POSS } \\
\text { polyamide }\end{array}$ & + & + & + & + & - & - & - & - & - \\
\hline
\end{tabular}

${ }^{1}+$ : Soluble at room temperature, -: Insoluble at room temperature. ${ }^{2}$ Abbreviation of solvents, DMSO: Dimethyl sulfoxide, DMF: $N, N-$ Dimethylformamide, $\mathrm{MeOH}$ : Methanol, $\mathrm{Me}_{2} \mathrm{CO}$ : Acetone, AcOEt: Ethyl acetate, $\mathrm{CHCl}_{3}$ : Chloroform.

The structure of the resulting product was determined by FT-IR, ${ }^{1} \mathrm{H}$ NMR, and ${ }^{29} \mathrm{Si}$ NMR measurements. In the FT-IR spectrum of POSS polyamide, a single absorption peak at $1119 \mathrm{~cm}^{-1}$ attributed to the Si-O-Si bond and that ascribed to carbonyl (carboxyl and amide) groups was observed (Figure 1). It has been reported that the FT-IR spectra of POSS show a single peak ascribed to the $\mathrm{Si}-\mathrm{O}-\mathrm{Si}$ stretching absorption band because of their high symmetrical structures [49].

In the ${ }^{1} \mathrm{H}$ NMR spectrum of POSS polyamide in DMSO- $d_{6}$ (Figure 2c), in addition to the signal attributed to the side chain of each POSS, the signal $i$ " attributed to the methylene proton adjacent to the $\mathrm{N}$ atom of the amide bond was observed, suggesting the formation of the amide bonds. In addition, calculations based on the integral ratio of the signals $\mathrm{d}^{\prime \prime}$ to $\mathrm{e}^{\prime \prime}$ (2.2:5.8) suggest that an average of two amide bonds was formed in the POSS-A component, assuming that POSS-A is an octamer. Meanwhile, calculations based on the integral ratio of signals $\mathbf{d}^{\prime \prime}$ to $\mathrm{f}^{\prime \prime}$ (2.5:7.5) reveal that an average of two to three amide bonds was formed in the POSS-C component, assuming that POSS-C is a decamer. Furthermore, calculations based on the integral ratio of the signals $\mathbf{e}^{\prime \prime}$ to $\mathbf{f}^{\prime \prime}$ show that POSS-A and POSS-C components exist at a unit ratio of 47:53, which is almost the same as the feed molar ratio. 


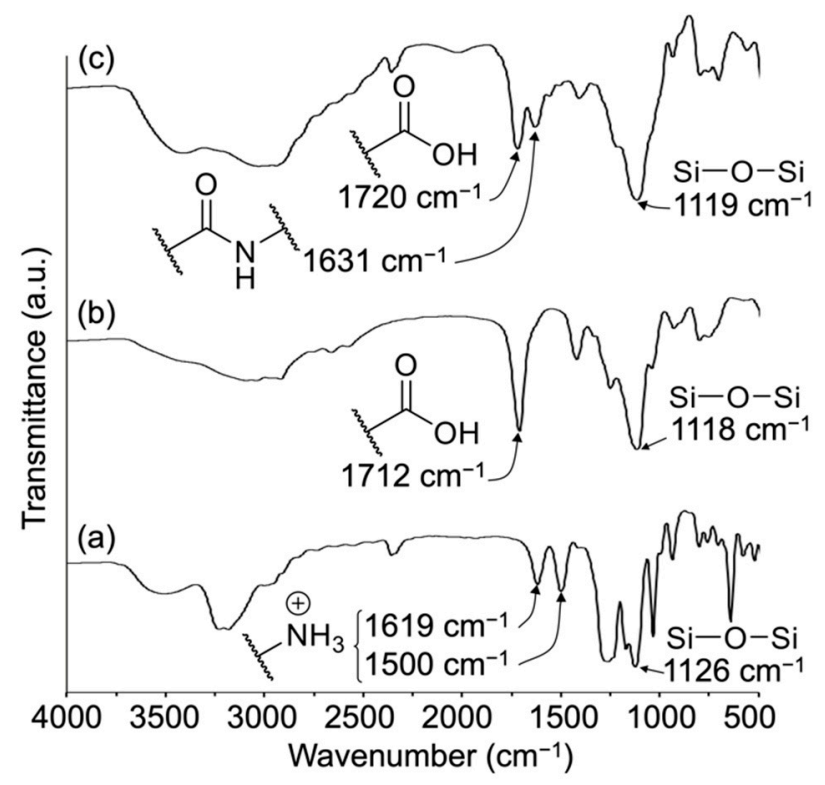

Figure 1. FT-IR spectra of (a) POSS-A, (b) POSS-C, and (c) POSS polyamide in KBr pellets.
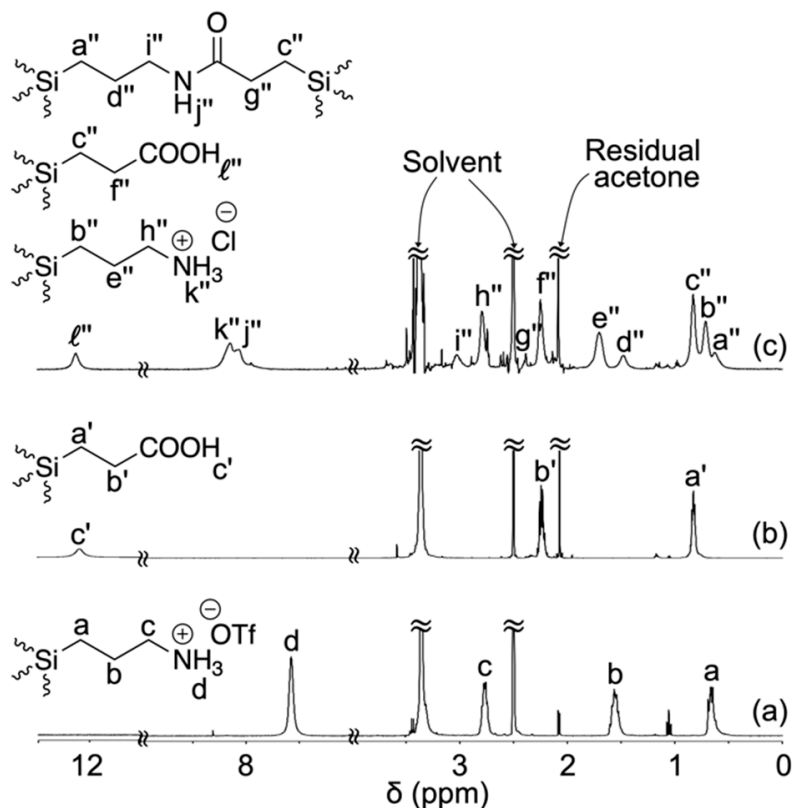

Figure 2. ${ }^{1} \mathrm{H}$ NMR spectra of (a) POSS-A, (b) POSS-C, and (c) POSS polyamide in DMSO- $d_{6}$. The chemical shifts are referenced to DMSO- $d_{6}(\delta 2.5)$.

In the ${ }^{29} \mathrm{Si}$ NMR spectrum of POSS polyamide in DMSO- $d_{6}$, some signals attributed to only $\mathrm{T}^{3}$ structure were observed (Figure 3c), indicating that the POSS framework was maintained even after the polycondensation. According to previous studies on POSS containing alkyl side chains $[43,45,47,50]$, the signals at -65.3 to $-66.9,-66.9$ to -69.5 , and -69.5 to $-71.4 \mathrm{ppm}$ are attributed to $\mathrm{T}_{8}-\mathrm{POSS}, \mathrm{T}_{10}-\mathrm{POSS}$, and $\mathrm{T}_{12}$-POSS, respectively.

The plausible mechanism of the formation of a soluble POSS polyamide is shown below. In the condensation of POSS-A and POSS-C using the aforementioned system of condensing agents, the amino and carboxyl groups of the POSS side chains adjacent to the amide bond were difficult to react due to steric hindrance. Consequently, we infer that the amino and carboxyl groups of the POSS side chains located on the opposite side of the amide-bond site are likely to react, resulting in a polymer in which the POSS units are linearly connected. 


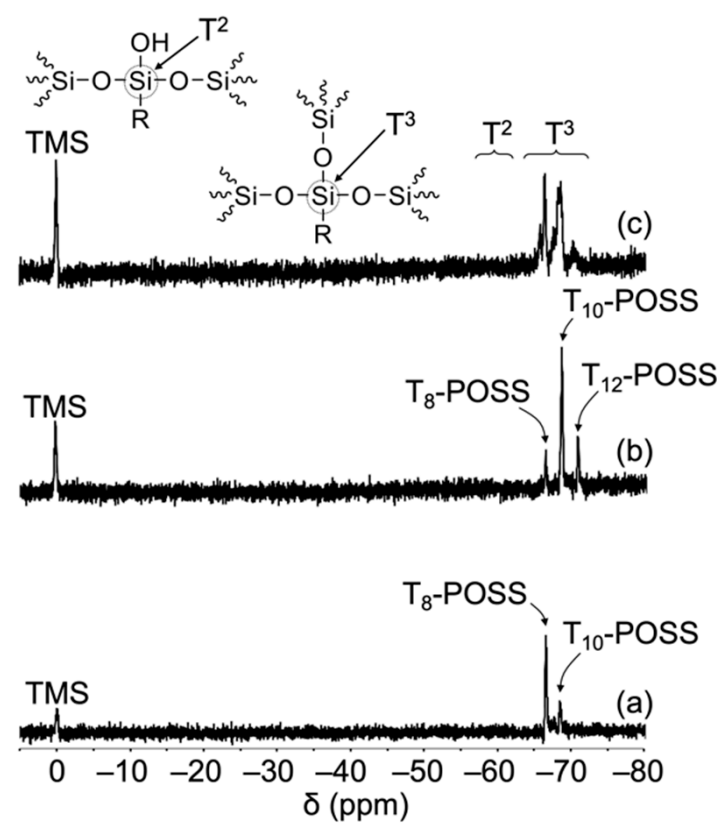

Figure 3. ${ }^{29} \mathrm{Si}$ NMR spectra of (a) POSS-A, (b) POSS-C, and (c) POSS polyamide in DMSO- $d_{6}$ at $40{ }^{\circ} \mathrm{C}$. A small amount of $\mathrm{Cr}(\mathrm{acac})_{3}$ was added as a relaxation agent. The chemical shifts are referenced to TMS $(\delta 0.0)$.

\subsection{Self-Standing Film Formability of POSS Polyamide}

POSS polyamide and the starting materials (POSS-C and POSS-A) were dissolved in methanol, and the solutions were heated $\left(\mathrm{ca} .50^{\circ} \mathrm{C}\right)$ on trays to evaporate the methanol. Consequently, POSS-A was powdery (Figure 4a), and POSS-C was sticky (Figure $4 \mathrm{~b}$ ), whereas POSS polyamide formed a self-standing film (Figure 4c). The average molecular weight could not be accurately estimated by GPC measurements, probably due to the presence of ionic substituents in POSS polyamide. However, since POSS polyamide could form a self-standing film, we infer that it is a polymer with a relatively high average molecular weight.

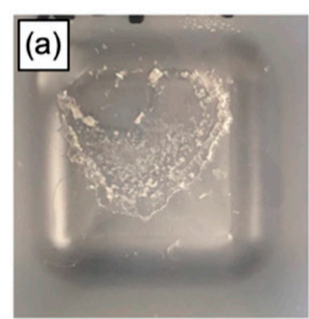

Powdery solid

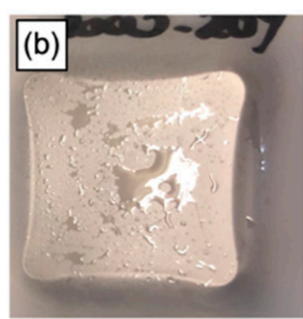

Sticky solid

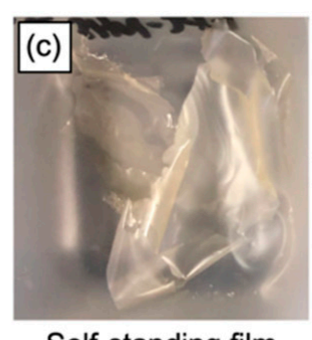

Self-standing film

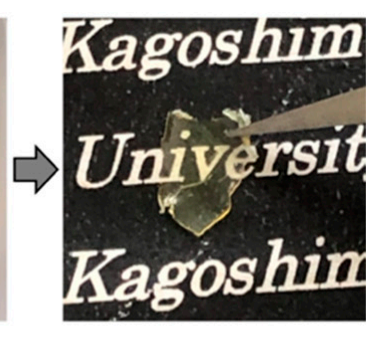

Figure 4. Photographs after evaporating methanol solutions of (a) POSS-A, (b) POSS-C, and (c) POSS polyamide.

\subsection{Thermal Properties of POSS Polyamide}

TGA thermograms of POSS polyamide and the starting materials are shown in Figure 5 . The $5 \%$ and $10 \%$ weight-loss temperatures $\left(T_{\mathrm{d} 5}\right.$ and $\left.T_{\mathrm{d} 10}\right)$ of POSS polyamide (Figure 5c) were lower than those of the starting materials: POSS-A (Figure 5a) and POSSC (Figure 5b). Furthermore, we confirmed that weight loss in POSS polyamide occurred in two stages. The first stage of weight loss is attributed to the evaporation of water and hydrogen chloride produced by the condensation of the ammonium and carboxyl groups of the side chains of POSS polyamide. We consider that the second stage of weight loss is a result of the decomposition of the alkyl side chains. The TG measurement of the POSS polyamide film heat-treated at $400^{\circ} \mathrm{C}$ for $30 \mathrm{~min}$ was further investigated. The film 
maintained its transparency (color became slightly darker) and shape even after the above heat treatment (inserted photograph in Figure 6). The $T_{\mathrm{d} 5}$ value of the heat-treated POSS polyamide was ca. $500{ }^{\circ} \mathrm{C}$, indicating high thermal stability (Figure 6).

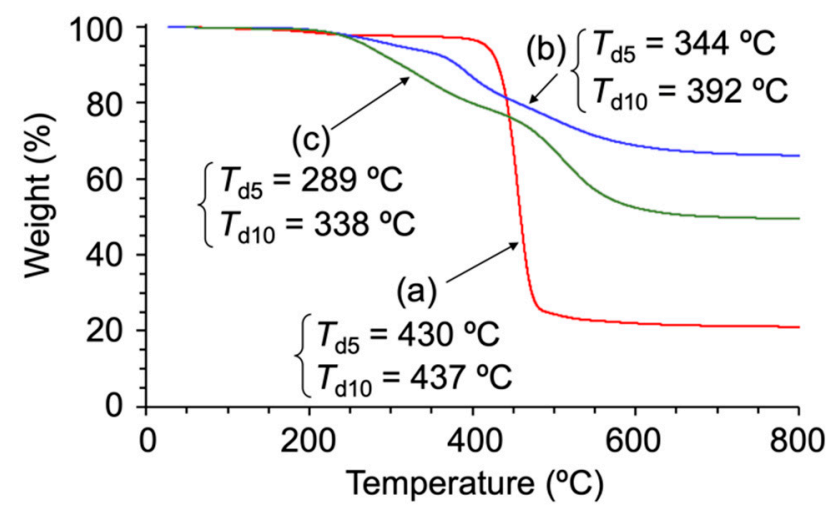

Figure 5. TGA thermograms of (a) POSS-A, (b) POSS-C, and (c) POSS polyamide.

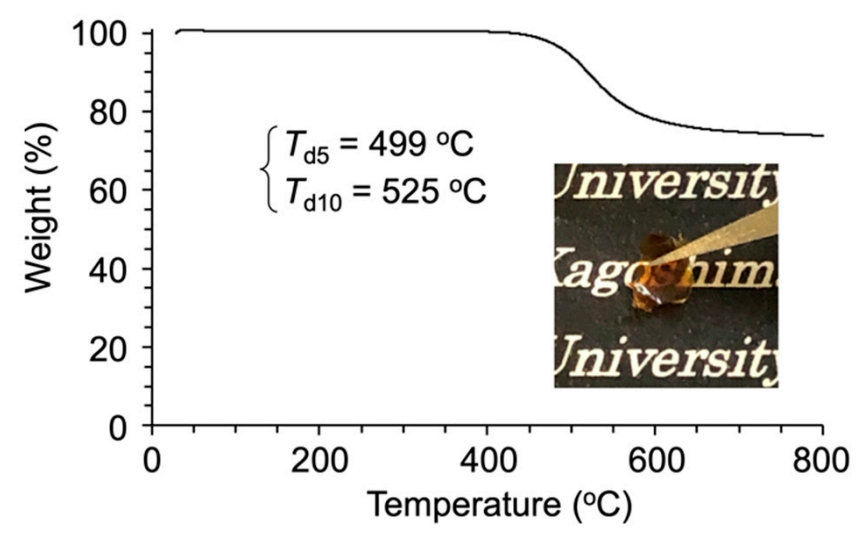

Figure 6. TGA thermogram of POSS polyamide after heat treatment at $400{ }^{\circ} \mathrm{C}$ for $30 \mathrm{~min}$. The inserted photograph shows the state of the heat-treated POSS polyamide film.

\subsection{Hard-Coating and Antifogging Properties of a POSS Polyamide Cast Film}

A POSS polyamide cast film was prepared as follows. An aqueous solution of POSS polyamide (POSS polyamide $/$ water $=25 \mathrm{mg} / 0.10 \mathrm{~mL}$ ) was applied on a glass plate and then heated at ca. $80^{\circ} \mathrm{C}$ in an open system for $30 \mathrm{~min}$ to evaporate the water. The resulting cast film was further heated in an oven at $150{ }^{\circ} \mathrm{C}$ for $30 \mathrm{~min}$. This cast film was highly transparent (Figure 7a). Comparing the FT-IR spectra of the cast film before (Figure $7 \mathrm{~b}$ ) and after (Figure $7 \mathrm{c}$ ) heating at $150{ }^{\circ} \mathrm{C}$ for $30 \mathrm{~min}$, the absorption peak ascribed to the amide bond slightly increased after heating.

The hardness of the resulting cast film was evaluated by a pencil scratch test. The film was scratched at $6 \mathrm{H}$ and was not scratched at $5 \mathrm{H}$, implying that the pencil hardness of the POSS polyamide cast film was $5 \mathrm{H}$. As a comparison, the pencil hardness of the cast film before heating was $2 \mathrm{H}$ to $3 \mathrm{H}$. We infer that the POSS polyamide cast film exhibited a relatively higher hardness because amide bonds increased to form a cross-linked structure, in addition to the rigidity of the original POSS.

Further, the antifogging performance of the POSS polyamide cast film was evaluated by placing the cast-film surface facing down at a distance of ca. $5 \mathrm{~cm}$ from hot water at ca. $80^{\circ} \mathrm{C}$ and exposing it to water vapor (Figure 8a). Consequently, the film was transparent at first (showing antifogging properties) (Figure $8 \mathrm{~b}$ ), but it became cloudy in the middle (Figure 8c), and finally, it showed antifogging properties again (Figure 8d). The reason for such changes in antifogging property is described in a later section. We attributed that the antifogging property to the high hydrophilicity of the cast film surface; hence, we measured 
the water contact angle. However, it was relatively high $\left(68^{\circ}\right.$, Figure 9$)$. This is probably because the amide bonds increased, and a porous cross-linked structure was formed in the cast film after heat treatment. As a result, even though the POSS polyamide cast film contained a large amount of hydrophilic ammonium chloride and carboxyl groups, the contact angle of water droplets became relatively high due to the lotus-leaf effect.

(a)

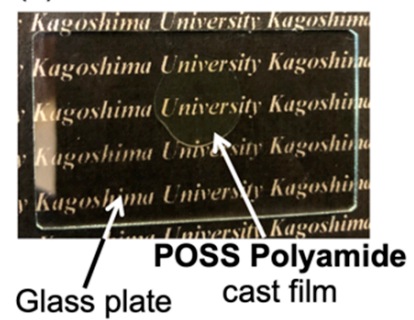

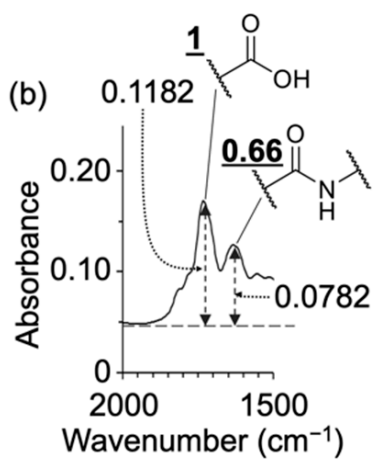

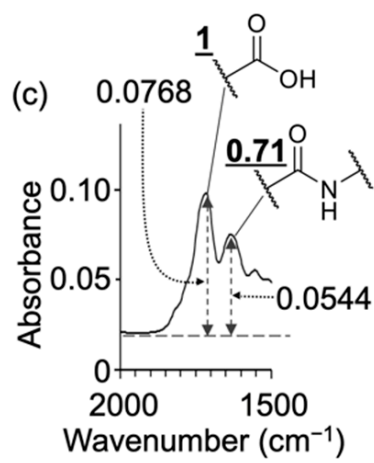

Figure 7. (a) Photograph of a POSS polyamide cast film after heat treatment at $150{ }^{\circ} \mathrm{C}$ for $30 \mathrm{~min}$. FT-IR spectra (KBr pellets) of a POSS polyamide cast film (b) before and (c) after heat treatment at $150{ }^{\circ} \mathrm{C}$ for $30 \mathrm{~min}$.

(a)
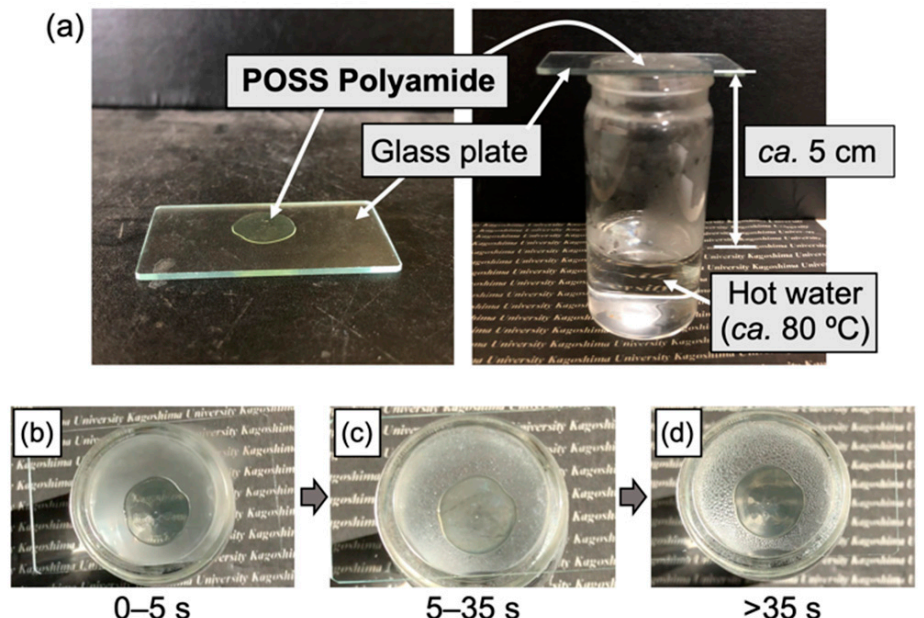

Figure 8. (a) Exposure of a POSS polyamide cast film to water vapor, and appearances of (b) $0-5 \mathrm{~s}$, (c) 5-35 s, and (d) $>35 \mathrm{~s}$ after exposure to water vapor.

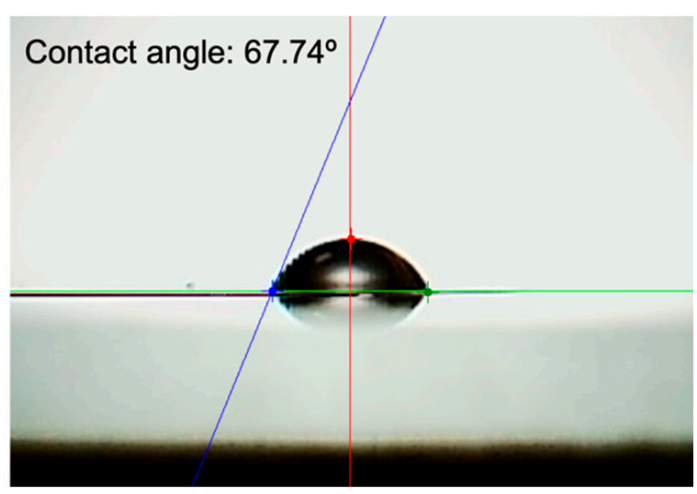

Figure 9. Water contact angle of a POSS polyamide cast film. 
On the other hand, in the case of exposure to water vapor, water molecules could penetrate the porous structure as water vapor, and the water generated by cooling first fills the pores in the cast film surface. Thus, the hydrophilicity of the cast film surface is increased, and a thin water film may be formed. Consequently, no light scattering occurs, and the film becomes transparent at first (0-5 s after exposure to water vapor; Figure 10a). After a while, the water on the surface gradually penetrates the inside. At this time, the water in the pores is not uniform; thus, light is scattered, and the cast film becomes cloudy (5-35 s after exposure to water vapor; Figure 10b). Finally, the pores inside the cast film are filled with water, allowing light to pass through without scattering ( $>35 \mathrm{~s}$ after exposure to water vapor; Figure 10c). This suggests that the cast film exhibits antifogging properties again.

(a)

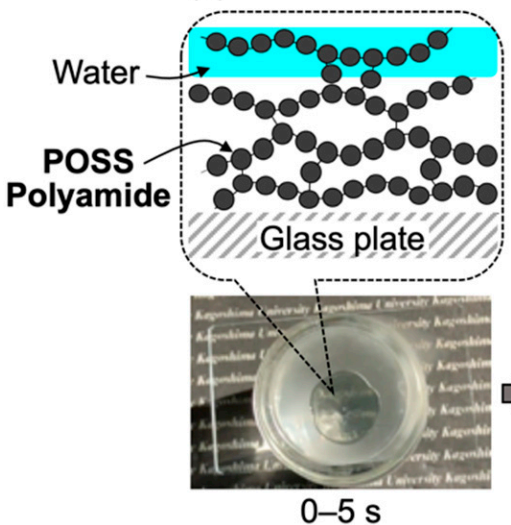

(b)

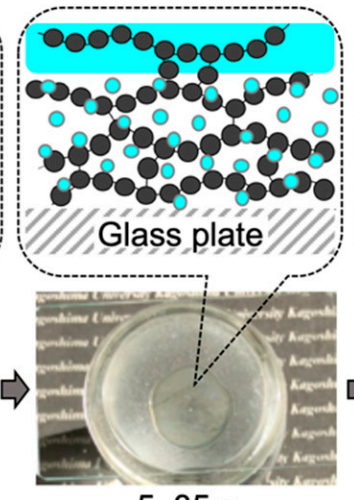

$5-35 \mathrm{~s}$ (c)

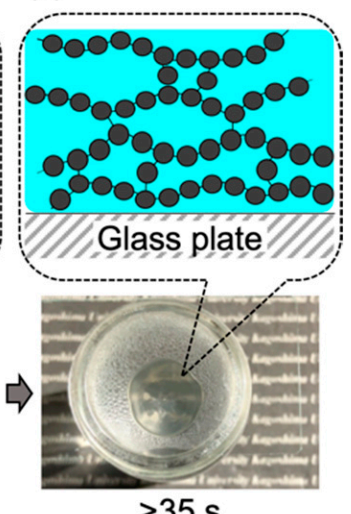

Figure 10. Expected mechanism of the changing antifogging property: appearances of water in a POSS polyamide cast film at (a) 0-5 s, (b) 5-35 s, and (c) $>35 \mathrm{~s}$ after exposure to water vapor.

3.5. Effect of the Heat-Treatment Temperature on the Antifogging and Hard-Coating Properties of POSS Polyamide Cast Film

The effect of the heat-treatment temperature on the antifogging and hard-coating properties of POSS polyamide cast film was investigated. The cast film heat-treated at $100{ }^{\circ} \mathrm{C}$ for 30 min showed antifogging properties but not hard-coating properties (Figure 11a). On the other hand, the cast films treated at above $150{ }^{\circ} \mathrm{C}$ for $30 \mathrm{~min}$ exhibited hard-coating properties but not antifogging properties (Figure 11c-e). Although the details of the heat-treatment temperature were not investigated, $150{ }^{\circ} \mathrm{C}$ seemed to be optimum.

\begin{tabular}{|l|c|c|c|c|c|}
\hline & (a) $100^{\circ} \mathrm{C}$ & (b) $150^{\circ} \mathrm{C}$ & (c) $160^{\circ} \mathrm{C}$ & (d) $170{ }^{\circ} \mathrm{C}$ & (e) $180^{\circ} \mathrm{C}$ \\
\hline $\begin{array}{c}\text { Appearance } \\
\text { of cast film }\end{array}$ & Transparent & Transparent & Transparent & Transparent & Transparent \\
\hline $\begin{array}{c}\text { Antifogging } \\
\text { property }\end{array}$ & Good & Good & Bad & Bad & Bad \\
\hline $\begin{array}{c}\text { Hard-coating } \\
\text { property }\end{array}$ & $2-3 \mathrm{H}$ & $5 \mathrm{H}$ & $5 \mathrm{H}$ & $6 \mathrm{H}$ & $6 \mathrm{H}$ \\
\hline
\end{tabular}

Figure 11. Antifogging and hard-coating properties of POSS polyamide cast films heat-treated at (a) $100{ }^{\circ} \mathrm{C}$, (b) $150{ }^{\circ} \mathrm{C}$, (c) $160^{\circ} \mathrm{C}$, (d) $170{ }^{\circ} \mathrm{C}$, and (e) $180^{\circ} \mathrm{C}$ for $30 \mathrm{~min}$. 


\subsection{Antifogging and Hard-Coating Properties of Cast Films of the Starting Materials}

The antifogging and hard-coating properties of the starting materials (POSS-A and POSS-C) and their mixture were investigated. Since the counterion of the POSS-A component in POSS polyamide is a chloride ion (derived from EDC), POSS-A, whose counterion is a chloride ion, was used here. The cast films of the starting materials were heat-treated at $150{ }^{\circ} \mathrm{C}$ for $30 \mathrm{~min}$, the condition under which the POSS polyamide cast film exhibited both antifogging and hard-coating properties.

The POSS-A cast film was opaque, and it was scratched even at 3B in the pencil scratch test (Figure 12a). Due to the POSS-A cast film being opaque, the antifogging property could not be evaluated. Meanwhile, the POSS-C cast film was transparent, and the pencil hardness was $6 \mathrm{H}$, indicating excellent hard-coating properties; however, the antifogging property could not be evaluated (Figure 12b). The cast film prepared from a mixture of POSS-A and POSS-C exhibited hard-coating but not antifogging properties (Figure 12c). From the above results, we conclude that it is difficult for the cast films of POSS-A, POSS$\mathrm{C}$, and their mixture to achieve both antifogging and hard-coating properties, and it is important to covalently link the POSS to form a polymer.

\begin{tabular}{|c|c|c|c|}
\hline & $\begin{array}{c}\text { (a) POSS-A } \\
\left.\text { (Counterion: } \mathrm{Cl}^{-}\right)\end{array}$ & (b) POSS-C & $\begin{array}{c}\text { (c) Mixture of POSS-A } \\
\text { and POSS-C }\end{array}$ \\
\hline $\begin{array}{c}\text { Appearance } \\
\text { of cast film }\end{array}$ & opaque & Transparent & \\
\hline $\begin{array}{c}\text { Antifogging } \\
\text { property }\end{array}$ & - & Transparent \\
\hline $\begin{array}{c}\text { Hard-coating } \\
\text { property }\end{array}$ & $<3 \mathrm{~B}$ & $6 \mathrm{H}$ & $\mathrm{Bad}$ \\
\hline
\end{tabular}

Figure 12. Antifogging and hard-coating properties of (a) POSS-A cast film, (b) POSS-C cast film, and (c) cast film prepared from a mixture of POSS-A and POSS-C.

\section{Conclusions}

In this study, POSS polyamide was prepared by the polycondensation of POSS-A and POSS-C in dehydrated DMSO using EDC and NHS as the condensing agents. POSS polyamide was soluble in various highly polar solvents, and it could form a self-standing film. Furthermore, the cast film obtained by heat-treating the polymer at $150{ }^{\circ} \mathrm{C}$ for 30 min was transparent and exhibited excellent hard-coating (pencil scratch test: $5 \mathrm{H}$ ) and antifogging properties (evaluation by water vapor exposure).

Author Contributions: Conceptualization, Y.K.; methodology, T.K.; formal analysis, T.K. and A.M.; investigation, T.K.; resources, Y.K.; data curation, T.K.; writing-original draft preparation, T.K.; writing-review and editing, Y.K.; supervision, Y.K.; project administration, Y.K.; funding acquisition, Y.K. All authors have read and agreed to the published version of the manuscript.

Funding: This research received no external funding.

Institutional Review Board Statement: Not applicable.

Informed Consent Statement: Not applicable.

Data Availability Statement: Data is contained within the article.

Conflicts of Interest: The authors declare no conflict of interest. 


\section{References}

1. Wang, Y.; Gong, X. Special oleophobic and hydrophilic surfaces: Approaches, mechanisms, and applications. J. Mater. Chem. A 2017, 5, 3759-3773. [CrossRef]

2. Zhao, J.; Song, L.; Ming, W. Antifogging and Frost-Resisting Polymeric Surfaces. Adv. Polym. Sci. 2018, 284, 185-214. [CrossRef]

3. Gao, X.; Yan, X.; Yao, X.; Xu, L.; Zhang, K.; Zhang, J.; Yang, B.; Jiang, L. The Dry-Style Antifogging Properties of Mosquito Compound Eyes and Artificial Analogues Prepared by Soft Lithography. Adv. Mater. 2007, 19, 2213-2217. [CrossRef]

4. Liu, K.; Yao, X.; Jiang, L. Recent developments in bio-inspired special wettability. Chem. Soc. Rev. 2010, 39, 3240-3255. [CrossRef]

5. Sun, Z.; Liao, T.; Liu, K.; Jiang, L.; Kim, J.H.; Dou, S.X. Fly-Eye Inspired Superhydrophobic Anti-Fogging Inorganic Nanostructures. Small 2014, 10, 3001-3006. [CrossRef]

6. Wang, R.; Hashimoto, K.; Fujishima, A.; Chikuni, M.; Kojima, E.; Kitamura, A.; Shimohigoshi, M.; Watanabe, T. Light-induced amphiphilic surfaces. Nature 1997, 388, 431-432. [CrossRef]

7. Wang, R.; Hashimoto, K.; Fujishima, A.; Chikuni, M.; Kojima, E.; Kitamura, A.; Shimohigoshi, M.; Watanabe, T. Photogeneration of highly amphiphilic $\mathrm{TiO}_{2}$ surfaces. Adv. Mater. 1998, 10, 135-138. [CrossRef]

8. Sun, R.-D.; Nakajima, A.; Fujishima, A.; Watanabe, T.; Hashimoto, K. Photoinduced Surface Wettability Conversion of ZnO and $\mathrm{TiO}_{2}$ Thin Films. J. Phys. Chem. B 2001, 105, 1984-1990. [CrossRef]

9. Zhang, X.-T.; Sato, O.; Taguchi, M.; Einaga, Y.; Murakami, T.; Fujishima, A. Self-Cleaning Particle Coating with Antireflection Properties. Chem. Mater. 2005, 17, 696-700. [CrossRef]

10. Lee, D.; Rubner, M.F.; Cohen, R.E. All-Nanoparticle Thin-Film Coatings. Nano Lett. 2006, 6, 2305-2312. [CrossRef]

11. Tricoli, A.; Righettoni, M.; Pratsinis, S.E. Anti-Fogging Nanofibrous $\mathrm{SiO}_{2}$ and Nanostructured $\mathrm{SiO}_{2}-\mathrm{TiO}_{2}$ Films $\mathrm{Made}$ by Rapid Flame Deposition and In Situ Annealing. Langmuir 2009, 25, 12578-12584. [CrossRef]

12. Chemin, J.-B.; Bulou, S.; Baba, K.; Fontaine, C.; Sindzingre, T.; Boscher, N.D.; Choquet, P. Transparent anti-fogging and selfcleaning $\mathrm{TiO}_{2} / \mathrm{SiO}_{2}$ thin films on polymer substrates using atmospheric plasma. Sci. Rep. 2018, 8, 1-8. [CrossRef]

13. Ye, L.; Zhang, Y.; Song, C.; Li, Y.; Jiang, B. A simple sol-gel method to prepare superhydrophilic silica coatings. Mater. Lett. 2017, 188, 316-318. [CrossRef]

14. Zhao, J.; Meyer, A.; Ma, L.; Ming, W. Acrylic coatings with surprising antifogging and frost-resisting properties. Chem. Commun. 2013, 49, 11764-11766. [CrossRef]

15. Lee, H.; Alcaraz, M.L.; Rubner, M.F.; Cohen, R.E. Zwitter-Wettability and Antifogging Coatings with Frost-Resisting Capabilities. ACS Nano 2013, 7, 2172-2185. [CrossRef]

16. Zhao, J.; Meyer, A.; Ma, L.; Wang, X.; Ming, W. Terpolymer-based SIPN coating with excellent antifogging and frost-resisting properties. RSC Adv. 2015, 5, 102560-102566. [CrossRef]

17. Bai, S.; Li, X.; Zhang, R.; Li, C.; Zhu, K.; Sun, P.; Zhao, Y.; Ren, L.; Yuan, X. Enhancing antifogging/frost-resisting performances of amphiphilic coatings via cationic, zwitterionic or anionic polyelectrolytes. Chem. Eng. J. 2019, 357, 667-677. [CrossRef]

18. Zhang, T.; Fang, L.; Lin, N.; Wang, J.; Wang, Y.; Wu, T.; Song, P. Highly transparent, healable, and durable anti-fogging coating by combining hydrophilic pectin and tannic acid with poly(ethylene terephthalate). Green Chem. 2019, 21, 5405-5413. [CrossRef]

19. Zhao, J.; Lu, P.; Song, L.; Tian, L.; Ming, W.; Ren, L. Highly efficient antifogging and frost-resisting acrylic coatings from one-step thermal curing. Colloids Surf. A Physicochem. Eng. Asp. 2020, 585, 124160. [CrossRef]

20. Howarter, J.A.; Youngblood, J.P. Self-Cleaning and Next Generation Anti-Fog Surfaces and Coatings. Macromol. Rapid Commun. 2008, 29, 455-466. [CrossRef]

21. Yao, B.; Zhao, H.; Wang, L.; Liu, Y.; Zheng, C.; Li, H.; Sun, C. Synthesis of acrylate-based UV/thermal dual-cure coatings for antifogging. J. Coat. Technol. Res. 2017, 15, 149-158. [CrossRef]

22. Baney, R.H.; Itoh, M.; Sakakibara, A.; Suzuki, T. Silsesquioxanes. Chem. Rev. 1995, 95, 1409-1430. [CrossRef]

23. Loy, D.A.; Baugher, B.M.; Baugher, C.R.; Schneider, D.A.; Rahimian, K. Substituent effects on the sol-gel chemistry of organotrialkoxysilanes. Chem. Mater. 2000, 12, 3624-3632. [CrossRef]

24. Cordes, D.; Lickiss, P.D.; Rataboul, F. Recent Developments in the Chemistry of Cubic Polyhedral Oligosilsesquioxanes. Chem. Rev. 2010, 110, 2081-2173. [CrossRef]

25. Laine, R.M.; Roll, M.F. Polyhedral Phenylsilsesquioxanes. Macromolecules 2011, 44, 1073-1109. [CrossRef]

26. Kuo, S.-W.; Chang, F.-C. POSS related polymer nanocomposites. Prog. Polym. Sci. 2011, 36, 1649-1696. [CrossRef]

27. Wang, F.; Lu, X.; He, C. Some recent developments of polyhedral oligomeric silsesquioxane (POSS)-based polymeric materials. J. Mater. Chem. 2011, 21, 2775-2782. [CrossRef]

28. Tanaka, K.; Chujo, Y. Advanced functional materials based on polyhedral oligomeric silsesquioxane (POSS). J. Mater. Chem. 2012, 22, 1733-1746. [CrossRef]

29. Kaneko, Y.; Toyodome, H.; Shoiriki, M.; Iyi, N. Preparation of ionic silsesquioxanes with regular structures and their hybridization. Int. J. Polym. Sci. 2012, 2012, 684278. [CrossRef]

30. Kaneko, Y. Ionic silsesquioxanes: Preparation, structure control, characterization, and applications. Polymer 2018, 144, 205-224. [CrossRef]

31. Du, Y.; Liu, H. Cage-like silsesquioxanes-based hybrid materials. Dalton Trans. 2020, 49, 5396-5405. [CrossRef] [PubMed]

32. Tanaka, K.; Adachi, S.; Chujo, Y. Structure-property relationship of octa-substituted POSS in thermal and mechanical reinforcements of conventional polymers. J. Polym. Sci. Part A Polym. Chem. 2009, 47, 5690-5697. [CrossRef] 
33. Wu, S.; Hayakawa, T.; Kikuchi, R.; Grunzinger, A.S.J.; Kakimoto, M.-A.; Oikawa, H. Synthesis and Characterization of Semiaromatic Polyimides Containing POSS in Main Chain Derived from Double-Decker-Shaped Silsesquioxane. Macromolecules 2007, 40, 5698-5705. [CrossRef]

34. Wu, S.; Hayakawa, T.; Kakimoto, M.-A.; Oikawa, H. Synthesis and Characterization of Organosoluble Aromatic Polyimides Containing POSS in Main Chain Derived from Double-Decker-Shaped Silsesquioxane. Macromolecules 2008, 41, $3481-3487$. [CrossRef]

35. Jung, J.H.; Laine, R.M. Beads on a Chain (BOC) Polymers Formed from the Reaction of $\left.\mathrm{NH}_{2} \mathrm{PhSiO}_{1.5}\right]_{\mathrm{x}}\left[\mathrm{PhSiO}_{1.5}\right]_{10-\mathrm{x}}$ and $\left[\mathrm{NH}_{2} \mathrm{PhSiO}_{1.5}\right]_{x}\left[\mathrm{PhSiO}_{1.5}\right]_{12-\mathrm{x}}$ Mixtures $(\mathrm{x}=2-4)$ with the Diglycidyl Ether of Bisphenol A. Macromolecules 2011, 44, 7263-7272. [CrossRef]

36. Yoshimatsu, M.; Komori, K.; Ohnagamitsu, Y.; Sueyoshi, N.; Kawashima, N.; Chinen, S.; Murakami, Y.; Izumi, J.; Inoki, D.; Sakai, K.; et al. Necklace-shaped dimethylsiloxane polymers bearing a polyhedral oli-gomeric silsesquioxane cage prepared by polycondensation and ring-opening polymerization. Chem. Lett. 2012, 41, 622-624. [CrossRef]

37. Wei, K.; Wang, L.; Zheng, S. Organic-inorganic polyurethanes with 3,13-dihydroxypropyloctaphenyl double-decker silsesquioxane chain extender. Polym. Chem. 2012, 4, 1491-1501. [CrossRef]

38. Maegawa, T.; Irie, Y.; Fueno, H.; Tanaka, K.; Naka, K. Synthesis and polymerization of a para-disubstituted T8-caged hexaisobutylPOSS monomer. Chem. Lett. 2014, 43, 1532-1534. [CrossRef]

39. Maegawa, T.; Irie, Y.; Imoto, H.; Fueno, H.; Tanaka, K.; Naka, K. para-Bisvinylhexaisobutyl-substituted T 8 caged monomer: Synthesis and hydrosilylation polymerization. Polym. Chem. 2015, 6, 7500-7504. [CrossRef]

40. Tokunaga, T.; Koge, S.; Mizumo, T.; Ohshita, J.; Kaneko, Y. Facile preparation of a soluble polymer containing polyhedral oligomeric silsesquioxane units in its main chain. Polym. Chem. 2015, 6, 3039-3045. [CrossRef]

41. Kaneko, Y.; Shoiriki, M.; Mizumo, T. Preparation of cage-like octa(3-aminopropyl)silsesquioxane trifluoromethanesulfonate in higher yield with a shorter reaction time. J. Mater. Chem. 2012, 22, 14475-14478. [CrossRef]

42. Tokunaga, T.; Shoiriki, M.; Mizumo, T.; Kaneko, Y. Preparation of low-crystalline POSS containing two types of alkylammonium groups and its optically transparent film. J. Mater. Chem. C 2014, 2, 2496-2501. [CrossRef]

43. Imai, K.; Kaneko, Y. Preparation of Ammonium-Functionalized Polyhedral Oligomeric Silsesquioxanes with High Proportions of Cagelike Decamer and Their Facile Separation. Inorg. Chem. 2017, 56, 4133-4140. [CrossRef]

44. Matsumoto, T.; Kaneko, Y. Selective and high-yielding preparation of ammonium-functionalized cage-like octasilsesquioxanes using superacid catalyst in dimethyl sulfoxide. Chem. Lett. 2018, 47, 864-867. [CrossRef]

45. Matsumoto, T.; Kaneko, Y. Effect of Reaction Temperature and Time on the Preferential Preparation of Cage Octamer and Decamer of Ammonium-Functionalized POSSs. Bull. Chem. Soc. Jpn. 2019, 92, 1060-1067. [CrossRef]

46. Hasebe, R.; Kaneko, Y. Control of Crystalline-Amorphous Structures of Polyhedral Oligomeric Silsesquioxanes Containing Two Types of Ammonium Side-Chain Groups and Their Properties as Protic Ionic Liquids. Molecules 2019, 24, 4553. [CrossRef] [PubMed]

47. Kozuma, T.; Kaneko, Y. Preparation of carboxyl-functionalized polyhedral oligomeric silsesquioxane by a structural transformation reaction from soluble rod-like polysilsesquioxane. J. Polym. Sci. Part A Polym. Chem. 2019, 57, 2511-2518. [CrossRef]

48. Toyodome, H.; Kaneko, Y.; Shikinaka, K.; Iyi, N. Preparation of carboxylate group-containing rod-like polysilsesquioxane with hexagonally stacked structure by sol\&ndash;gel reaction of 2-cyanoethyltriethoxysilane. Polymer 2012, 53, 6021-6026. [CrossRef]

49. Park, E.S.; Ro, H.W.; Nguyen, C.V.; Jaffe, R.L.; Yoon, D.Y. Infrared Spectroscopy Study of Microstructures of Poly(silsesquioxane)s Chem. Mater. 2008, 20, 1548-1554. [CrossRef]

50. Chimjarn, S.; Kunthom, R.; Chancharone, P.; Sodkhomkhum, R.; Sangtrirutnugul, P.; Ervithayasuporn, V. Synthesis of aromatic functionalized cage-rearranged silsesquioxanes $\left(T_{8}, T_{10}\right.$, and $\left.T_{12}\right)$ via nucleophilic substitution reactions. Dalton Trans. 2015, 44, 916-919. [CrossRef] 